\title{
Incidence of cancer among workers producing calcium carbide
}

\author{
H KJUUS, ${ }^{1}$ A ANDERSEN, ${ }^{2}$ AND S LANGÅRD ${ }^{1}$ \\ From the Department of Occupational Medicine, ${ }^{1}$ Telemark Sentralsjukehus, N-3900 Porsgrunn, and the \\ Cancer Registry of Norway, ${ }^{2}$ Montebello, Oslo 3, Norway
}

\begin{abstract}
The overall mortality and the incidence of cancer have been studied among male employees at a plant producing calcium carbide. The cohort was defined as all men employed at the plant for at least 18 months in the period 1953 to 1970 and was classified according to 10 occupational categories. The 790 men have been observed from 1953 to 1983 and the incidence of cancer in the cohort has been compared with national incidence rates. A significant excess of colonic cancer (standardised incidence ratio, SIR $=2.09$ ) and of prostatic cancer (SIR $=1 \cdot 78$ ) was found, and also a slight excess of lung cancer among furnace and maintenance workers (SIR $=1.56)$. The possible exposure of the workers to polycyclic aromatic hydrocarbons, asbestos, and cadmium is discussed.
\end{abstract}

Several electrometallurgical processes involve the heating of carbonaceous electrode material during which volatile coal tar pitch products and, in particular, polycyclic aromatic hydrocarbons (PAH), may be released. These exposures, together with the occurrence of hot metals, asbestos, and a variety of known and unknown components in dust and fumes from such processes pose a potential health hazard to the workers concerned. An increased risk of cancer, and of lung cancer in particular, has been reported from several electrometallurgical industries. ${ }^{1-4}$ To our knowledge, no epidemiological study of cancer has been performed among employees in the calcium carbide industry.

Calcium carbide was traditionally produced for the purpose of illumination, mainly for the mining and the fishing industry. Today, its main use is in the industrial production of acetylene, used for welding and cutting, and in the manufacturing of calcium cyanamide and in the pyrotechnics industry. The major use of calcium cyanamide is as a fertiliser. It is also being increasingly used as a chemical intermediate in the production of dicyandiamide, which in turn may be polymerised to the widely used resin monomer, melamine.

The production of calcium carbide and of ferroalloys in Norway involves electrothermal reduction in three phase arc furnaces with Söderberg electrodes and carbon as the reduction agent. Both processes thereby imply exposure to common, potentially

Accepted 1 July 1985 harmful combustion products. In 1975 a cooperative study of the risk of cancer in the Norwegian ferroalloy and calcium carbide industry was initiated by the Health Board of the Norwegian Ferroalloy Industry. This report concerns the incidence of cancer in a cohort of calcium carbide producing workers; the results concerning the ferroalloy industry are presented elsewhere. ${ }^{5}$

\section{Production process}

The only plant in Norway producing calcium carbide was established in 1908 and is located in Odda, a small community at the head of one of the fjords in western Norway. Apart from calcium carbide, the plant has also produced calcium cyanamide and dicyandiamide for many years. In addition to the study plant there are two dominant metallurgical plants in the area that up to recently have produced zinc, cadmium, and aluminium.

The initial step in the production of calcium carbide is the burning of limestone to quicklime in a lime burner, where calcium carbonate is reduced to calcium oxide: $\mathrm{CaCO}_{3}=\mathrm{CaO}+\mathrm{CO}_{2}$. A mixture of crushed quicklime and coke or anthracite is then electrothermally reduced in two closed three phased arc furnaces with Söderberg electrodes at $2100^{\circ}$ Celsius: $\mathrm{CaO}+3 \mathrm{C}=\mathrm{CaC}_{2}+\mathrm{CO}$. In the presence of water, acetylene may develop: $\mathrm{CaC}_{2}+2 \mathrm{H}_{2} \mathrm{O}=\mathrm{C}_{2} \mathrm{H}_{2}+$ $\mathrm{Ca}(\mathrm{OH})_{2}$. At $1050^{\circ}$ Celsius calcium carbide reacts with nitrogen to form calcium cyanamide: $\mathrm{CaC}_{2}+$ $\mathrm{N}_{2}=\mathrm{CaCN}_{2}+\mathrm{C}$, which in turn is transformed to 
dicyandiamide in the presence of water and carbon dioxide.

The principal harmful exposures connected with the process are heat, and air pollution by calcium carbide, quicklime, anthracite dust, carbon monoxide, and acetylene. Calcium carbide exerts a pronounced effect on the skin and mucous membranes due to formation of calcium hydroxide on reaction with moisture or sweat. Impurities of calcium phosphate or calcium arsenate may, when moistened, give rise to the extremely toxic gases phosphine and arsine.

Exposure to PAH is not considered a general problem in the process, but some occupational tasks such as mantle welding and pitching of anode paste might include intermittent exposure. No measurements of polycyclic aromatic hydrocarbons have been performed at the plant. A hygienic survey of the dicyandiamide department in 1975 showed total dust concentrations in the range $10-25 \mathrm{mg} / \mathrm{m}^{3}$ in the packing room, 3-17 ppm ammonia, 0.2-0.8 ppm CO, and no trace of hydrogen sulphide, phosphine, or cyanide.

Asbestos has traditionally been used at the plant as an insulation material around the furnaces. The amount used in previous years is not known, but for the period 1978-82 there has been an annual consumption of $1000 \mathrm{~kg}$ of asbestos.

During the period 1924-68 there has been an annual average production of 40000 tons of calcium carbide, increasing to more than 100000 tons after 1968. The production of calcium cyanamide has been stable at around $\mathbf{4 0 0 0 0}$ tons during the same period. Production of dicyandiamide started in 1952 and during the past decades approximately $30 \%$ of the calcium cyanamide was processed further into dicyandiamide. The work force has gradually been reduced from about 600 in the 1930 s to 460 today.

\section{Material and methods}

The plant established a new personnel register in 1953 and provided complete personal records for all employees employed in 1953 or later. The personnel register for those who stopped working before 1953 had been destroyed, and no information was available for those employees. The work force has tradi-

\section{Table 1 Formation of the cohort}

\begin{tabular}{lr}
\hline & No \\
\hline Initial number of personal records: & \multicolumn{1}{c}{1055} \\
Women & 46 \\
Unidentified men & 35 \\
Incomplete employment data & 1 \\
Employed after 1 January 1970 or less than & 183 \\
$\quad 18$ months & \multicolumn{2}{c}{$\mathbf{7 9 0}$} \\
Ultimate cohort & \multicolumn{2}{c}{79} \\
\hline
\end{tabular}

tionally been stable, however, reflected by the fact that nearly $60 \%$ of those employed in the period 1953-69 had been employed for 10 years or more. Of the 1055 persons available for study, 46 women were excluded owing to their low number and absence of relevant occupational exposures. Personal identification numbers were initially missing for 645 of the male employees, but through local and national registry offices such identification was traced for most of them.

Altogether 35 or $3.5 \%$ of the cohort were lost to follow up. One person with incomplete employment data was excluded from the study. Subjects employed after 1 January 1970 or with a total employment time of less than 18 months were also excluded, leaving a cohort of 790 men for further examination. Table 1 gives a summary of the formation of the cohort.

The plant provided personnel records for all cohort members which included name, date of birth, period of employment, and place of work within the plant. Ten different occupational categories were defined, and each person was allocated to the category in which he had been employed for the longest time. A person with more than 10 years of furnace work was classified into the "furnace worker" category, irrespective of the duration of other jobs. Thirty eight subjects employed at the lime burner were also classified as furnace workers.

The cohort has been observed for total mortality and for the incidence of cancer and the follow up period has been 30 years, from 1 January 1953 to the end of 1982. As the cohort consisted of those working in 1953, this means that those who terminated their employment before 1953 but were still alive in that year were not included in the cohort. The cases of cancer were identified through the Cancer Registry of Norway, and the observed incidence of cancer in the cohort has been compared with the incidence of cancer in the total male Norwegian population. Further details concerning the identification of the cancer cases, together with the method used for estimating the expected figures, have been described elsewhere. ${ }^{5}$ Standardised mortality ratios (SMRs) have been calculated for overall mortality and standardised incidence ratios (SIRs) for selected cancer sites. Ninety five per cent confidence intervals $(\mathrm{CI})$ and two sided $\mathrm{p}$ values have been estimated, assuming a Poisson distribution for the observed number of cases.

\section{Results}

Table 2 shows the total mortality experience of the cohort and the total incidence of cancer during 1953-82. The 790 men accounted for 18779 personyears. The observed number of deaths were less than expected, with a SMR of 0.93. There were 92 cases of 
Table 2 Observed and expected number of deaths, and selected types of cancer among 790 employees at a calcium carbide plant, 1953-82. (Employed before 1 January 1970, employment time more than 18 months)

\begin{tabular}{|c|c|c|c|c|}
\hline $\begin{array}{l}\text { Cancer site } \\
\text { (ICD, 8th revision) }\end{array}$ & Observed & Expected & SMR-SIR & $95 \% \mathrm{CI} \dagger$ \\
\hline All deaths & 234 & 250.65 & 0.93 & $(0.81-1.06)$ \\
\hline $\begin{array}{l}\text { All cancer (140-207) } \\
\text { Lung }(162,163) \\
\text { Sinonasal (160) } \\
\text { Stomach (151) } \\
\text { Pancreas (157) } \\
\text { Colon (153) } \\
\text { Rectum (154) } \\
\text { Kidney (189) } \\
\text { Bladder (188) } \\
\text { Prostate (185) } \\
\text { Brain (191) } \\
\text { Leukaemia (204-207) } \\
\text { Malignant melanoma (172) } \\
\text { Other sites }\end{array}$ & $\begin{array}{r}92 \\
10 \\
0 \\
5 \\
3 \\
3 \\
12 \\
4 \\
4 \\
7 \\
75 \\
25 \\
2 \\
3 \\
3 \\
14\end{array}$ & $\begin{aligned} 76 \cdot 80 \\
8 \cdot 71 \\
0 \cdot 31 \\
10 \cdot 28 \\
3 \cdot 10 \\
5 \cdot 73 \\
3 \cdot 71 \\
2 \cdot 66 \\
4 \cdot 26 \\
14 \cdot 01 \\
1 \cdot 61 \\
2 \cdot 31 \\
1 \cdot 78 \\
18 \cdot 33\end{aligned}$ & $\begin{array}{l}1.20 \\
1.15 \\
0.49 \\
0.97 \\
2.09 * \\
1.08 \\
1.50 \\
1.64 \\
1.78^{*} \\
1.24 \\
1.20 \\
1.69 \\
0.76\end{array}$ & $\begin{array}{l}(0.98-1.48) \\
(0.55-2 \cdot 11) \\
(0 \cdot 16-1 \cdot 14) \\
(0 \cdot 19-2 \cdot 84) \\
(1.08-3.66) \\
(0.30-2.75) \\
(0.41-3.83) \\
(0.66-3.38) \\
(1 \cdot 16-2 \cdot 63) \\
(0.0-3.48) \\
(0.09-3 \cdot 12) \\
(0.11-4.04) \\
(0.42-1.28)\end{array}$ \\
\hline
\end{tabular}

*p $<0.05$.

$+95 \%$ Confidence interval.

cancer observed versus 76.8 expected (SIR $=1 \cdot 20)$. Looking at some selected forms of cancer, a statistically significant excess of colonic cancer (SIR $=2.09$ ) and of cancer of the prostate (SIR $=1.78)$ was observed, together with a non-significant increase in other urogenital cancers. There were 10 cases of lung cancer in the cohort, and 8.71 cases expected (SIR = $1 \cdot 15)$. There was an observed deficit of stomach cancer (SIR = 0.49), which was not statistically significant, however, owing to the low observed numbers.

Table 3 shows the observed and expected number of selected forms of cancer according to occupational category. There were six cases of lung cancer among furnace and maintenance workers combined, compared with the expected figure of 3.85 (SIR $=1.56$ ). The observed excess of cancer of the colon and of the prostate was distributed between several occupational categories. For furnace and maintenance workers combined there was a SIR for colonic cancer of $2 \cdot 30$ and for prostatic cancer of 1.98 . In the same group there was one case of stomach cancer versus 4.78 expected. No excess of cancer was observed among workers in the cyanamide/dicyandiamide production.

Table 4 shows the number of observed and expected cases of selected cancers by duration of employment. Six of the 10 cases of lung cancer occurred among employees with more than 25 years of total employment, but no dose-response relation was observed. There was no evident trend in SIR with employment time for any of the other cancers studied either. Nevertheless, nine of the 12 cases of colonic cancer and 20 of the 25 cases of prostatic cancer occurred among employees with employment time exceeding 25 years.

Table 5 shows total mortality, and incidence of selected cancers among those employed in two different employment periods (1920-49 and 1950-69). The mortality was similar for those employed before and after 1950 (SMR = 0.93 for both periods), but the observed excess of all cancer was seen mainly among those from the latter employment period. There were also higher SIRs for lung cancer and colonic cancer in the more recent employment period

Table 3 Observed $(O)$ and expected $(E)$ cases of selected types of cancer among 790 employees, 1953-82, by occupational category

\begin{tabular}{|c|c|c|c|c|c|c|c|c|c|c|c|}
\hline \multirow[t]{2}{*}{ Occupational category } & \multirow{2}{*}{$\begin{array}{l}\text { No } \\
\text { employed }\end{array}$} & \multicolumn{10}{|c|}{ Cancer site } \\
\hline & & \multicolumn{2}{|c|}{$\left.{ }_{O}^{\text {Lung }}{ }_{O}^{162}, 163\right)$} & \multicolumn{2}{|c|}{$\begin{array}{l}\text { Stomach } \\
(I C D \\
O\end{array}$} & \multicolumn{2}{|c|}{$\begin{array}{l}\text { Colon } \\
(\text { ICD 153) } \\
O\end{array}$} & \multicolumn{2}{|c|}{$\begin{array}{l}\text { Prostate } \\
\text { (ICD I85) } \\
O \quad C E\end{array}$} & \multicolumn{2}{|c|}{$\begin{array}{l}\text { All sites } \\
(\text { ICD } 140-209) \\
O \quad E\end{array}$} \\
\hline $\begin{array}{l}\text { Furnace } \\
\text { Maintenance } \\
\text { Quay, store, packing } \\
\text { Cyanamide/dicyandiamide } \\
\text { Construction, various jobs } \\
\text { Office, administration } \\
\text { Unspecified }\end{array}$ & $\begin{array}{r}179 \\
172 \\
66 \\
117 \\
167 \\
76 \\
13\end{array}$ & $\begin{array}{l}4 \\
2 \\
0 \\
1 \\
2 \\
1 \\
0\end{array}$ & $\begin{array}{l}2.20 \\
1.65 \\
0.73 \\
1.51 \\
1.74 \\
0.77 \\
0.11\end{array}$ & $\begin{array}{l}1 \\
0 \\
2 \\
0 \\
1 \\
0 \\
1\end{array}$ & $\begin{array}{l}2.84 \\
1.94 \\
0.75 \\
1.71 \\
1.99 \\
0.81 \\
0.24\end{array}$ & $\begin{array}{l}3 \\
3 \\
0 \\
1 \\
4 \\
1 \\
0\end{array}$ & $\begin{array}{l}1.53 \\
1.08 \\
0.47 \\
0.94 \\
1 \cdot 15 \\
0.46 \\
1 \cdot 10\end{array}$ & $\begin{array}{l}9 \\
4 \\
2 \\
1 \\
5 \\
3 \\
1\end{array}$ & $\begin{array}{l}4 \cdot 04^{*} \\
2 \cdot 52 \\
1 \cdot 08 \\
2 \cdot 28 \\
2 \cdot 77 \\
1 \cdot 00 \\
0 \cdot 32\end{array}$ & $\begin{array}{r}25 \\
14 \\
8 \\
11 \\
22 \\
10 \\
2\end{array}$ & $\begin{array}{r}20 \cdot 40 \\
14.62 \\
6.05 \\
12.66 \\
15 \cdot 34 \\
6 \cdot 29 \\
1.44\end{array}$ \\
\hline Total & 790 & 10 & 8.71 & 5 & $10 \cdot 28$ & 12 & $5 \cdot 73^{*}$ & 25 & $14.01^{*}$ & 92 & 76.80 \\
\hline
\end{tabular}

p $<0.05$. 
Table 4 Observed $(O)$ and expected $(E)$ number of selected types of cancer among 790 employees, 1953-82, according to duration of employment

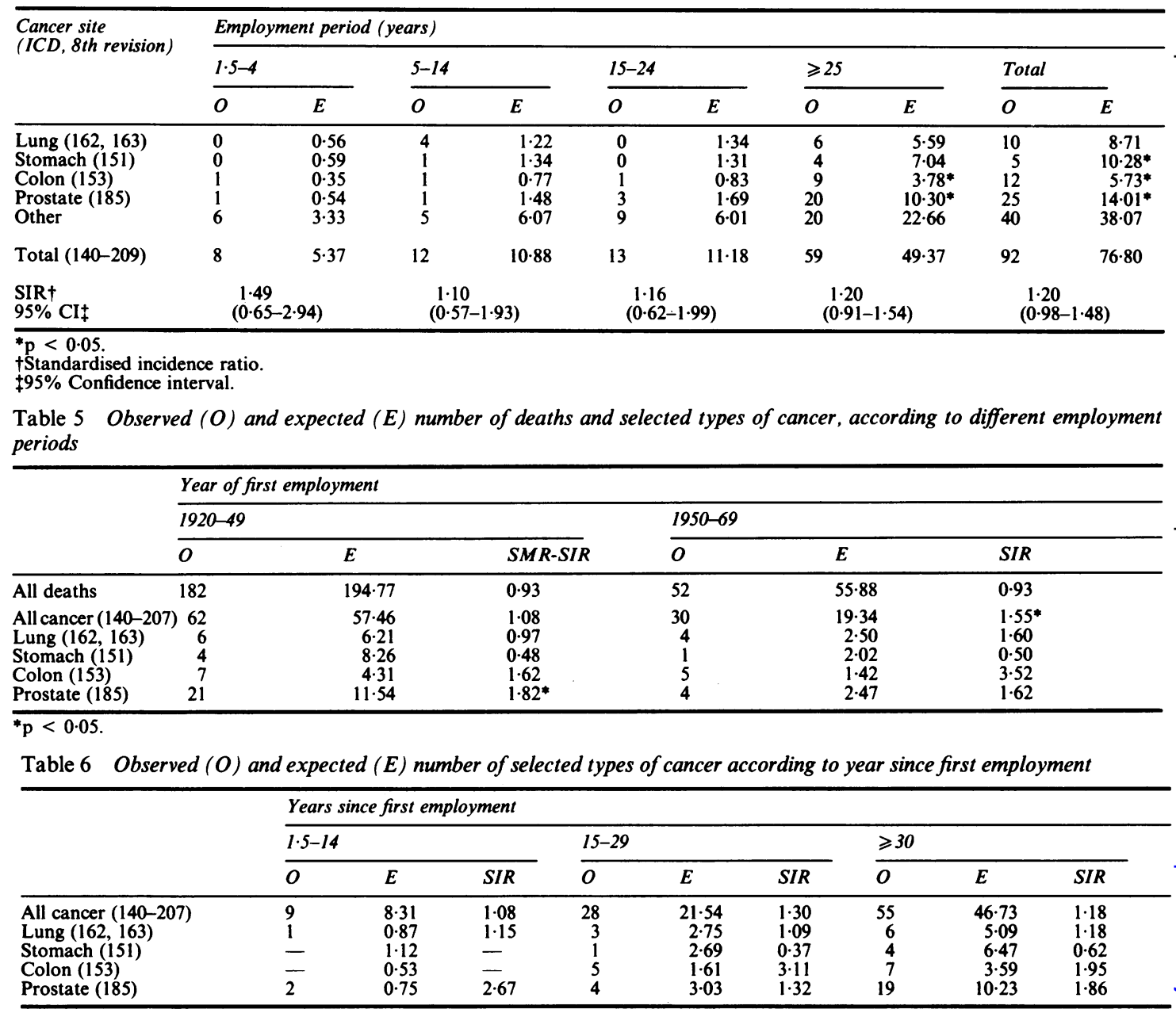

but not for stomach and prostatic cancer. For the selected cancer sites, however, the figures were too small for any definite trend to be evaluated.

Table 6 shows the mortality and incidence of selected cancers according to year since first employment. There was no obvious relation with follow up period for any of the cancers studied. If a 15 year "latency period" is introduced for lung cancer the SIR remains unchanged $($ SIR $=1 \cdot 15)$.

\section{Discussion}

When studying mortality and cancer incidence retrospectively in a plant based cohort, all those ever employed at the plant should ideally be eligible for cohort participation. Furthermore, the preferred $\frac{}{3}$ cohort formation would be that of an inception $>$ cohort, where all participants start their exposure at the time of admission into the cohort. ${ }^{6}$ These prem- $\bar{N}$ ises could not be fulfilled in the present study, and the $\Omega$ potential bias thereby introduced may have $N$ influenced the results in several ways. Firstly, that $\underset{\omega}{N}$ persons terminating employment before 1953 were $\sigma$ not eligible for the study implies an uncertain number

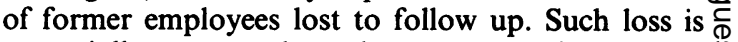
potentially outcome dependent, as some of those who $\stackrel{\oplus}{\rightarrow}$ left employment may have done so because of poor 0 health. Therefore, not only a primary healthy worker $\vec{O}$

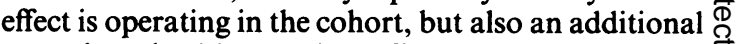
secondary healthy worker effect could possibly be $\underset{\mathbb{Q}}{\mathbb{Q}}$ 
present for the older part of the cohort. The deficit in mortality is moderate, however (SMR $=0.93$ ), and is identical in those employed before and those employed after 1950 (table 5). The possibility of a selective loss of deaths from the older part of the cohort is, therefore, not supported by these figures. In addition, during the observation period the mortality in the county in which the plant is located has been stable at around $93-95 \%$ of the national figures. The possible outcome dependent loss of cohort participation is, therefore, expected to be of a limited extent, and as the healthy worker effect is expected to influence mortality more than the incidence of cancer, ${ }^{7}$ a substantial deficit of cases of cancer in the observed cohort seems to be highly unlikely.

On the other hand, as the oldest part of the population studied may be considered as a "cross sectional" cohort, cumulative exposure of these subjects before cohort admission might lead to higher mortality figures than for an inception cohort with a similar exposure. ${ }^{6}$ The importance of this chronological bias, however, is dependent on the strength of association between exposure and effect, and does not seem to have played any important part in the present study. An observed overall SMR, similar to that observed in corresponding inception cohorts of ferroalloy workers in the same project, strengthens this assumption. $^{5}$

From the previous knowledge of potential exposures to carcinogenic agents connected with the calcium carbide process, the occurrence of respiratory cancer in the cohort is of particular interest. We know that asbestos has been in regular use at the plant in previous years, mainly as an insulation material around the furnaces and some additional use at the mechanic shop. Furthermore, it is known that the electrothermal reduction of iron containing ores with carbon in furnaces with Söderberg electrodes involves low grade exposure to PAH. As the same furnace equipment and reduction agents are used in the production of calcium carbide, the furnace workers at the study plant are also expected to have potentially sporadic exposures to PAH.

Although no significant excess of lung cancer in the total cohort was observed (SIR $=1 \cdot 15$ ), the highest SIR was observed among furnace and maintenance workers (6 cases observed, 3.85 expected). No trend in SIR was observed with duration of employment, however. Retrospective smoking information for the total cohort was not available, but a smoking survey was performed among all employees at the plant in 1977. Among 458 subjects, $59 \%$ were daily smokers, compared with $44 \%$ in the general male Norwegian population the same year. If this difference in smoking habits had also persisted in the past a slight confounding effect of smoking cannot be ruled out in the present study. ${ }^{8}$

The observed excess of colonic cancer was found mainly among long term employees, but did not seem to be associated with any particular occupational category. When studying the incidence of cancer among employees at five ferroalloy plants in another part of this project, the only plant with an observed excess of colonic cancer ( 11 cases observed, 5.8 expected) was a ferrosilicon plant, which also produced calcium carbide up to $1968 .^{5}$ We have no previous information, however, which might suggest an association between colonic cancer and agents related to the calcium carbide process.

Of the occupational exposure factors associated with colonic cancer, asbestos exposure seems to be among the best documented. 910 Since no definite excess of lung cancer was observed among the employees at the two plants, we are reluctant to suggest exposure to asbestos as a possible cause of the observed excess of colonic cancer in these cohorts.

Regional differences in the incidence of colonic cancer may explain some of the observed result, as the rural incidence rates of colonic cancer for the period $1972-6$ in the county in which the plant is located was $16 \%$ higher than the national figures for rural areas. ${ }^{11}$ Applying county rural rates to the cohort leads to a change in SIR from 2.09 to 1.80 , which is still a significant result.

A significant excess of cancer of the prostate was also observed in this cohort of calcium carbide workers. From table 7, it may be seen that a considerably higher incidence of prostatic cancer was observed in men in Odda municipality compared with both county and national figures. These observations are difficult to interpret. As prostatic cancer occurs mainly in old age, and is often diagnosed by chance at necropsy, the incidence figures reported to a national cancer registry from a region depend on the frequency of necropsy in the area. No more necropsies seem to have been performed during the study period at the local hospital than elsewhere in Norway (C Oulie: personal communication). In the period 1966-75, $1.1 \%$ of the prostatic cancers in the rural regions of western Norway have been registered on the basis of

Table 7 Annual age adjusted incidence rates of prostatic cancer (per 100000) in the periods 1955-69 and 1970-82 in the municipality under study compared with county and national rates

\begin{tabular}{lll}
\hline & Period & \\
\cline { 2 - 3 } & 1955-69 & $1970-82$ \\
& Incidence rate & Incidence rate \\
\hline Odda municipality & 57.5 & $110 \cdot 8$ \\
Hordaland county & 47.9 & $72 \cdot 2$ \\
Norway & 43.2 & 63.7 \\
\hline
\end{tabular}


accidental necropsy findings, compared with $1-3 \%$ in the remaining country, and $12 \%$ in the Oslo region. These figures indicate that the observed excess can hardly be explained by differential ascertainment of the diagnosis. Neither was there any difference in the mean age at diagnosis of prostatic cancer between the cases in the cohort and in the population at large. The possible contribution of occupational factors to the observed excess of prostatic cancer in these areas should therefore be considered.

An excess of prostatic cancer has been reported among a variety of occupational groups, but no common aetiological agent has as yet been identified. ${ }^{12}$ Several studies have shown increased risk for prostatic cancer associated with exposure to cadmium possibly related to cadmium as a zinc antagonist. ${ }^{13}$ No known exposure to cadmium occurs at the plant but another plant in the same village has produced both zinc and cadmium for many years. Interchange of workers between the study plant and the zinc plant has been traditional in this small community, but further investigation showed that only one of the 25 men with prostatic cancer had been employed at the other plant. He had worked in the zinc pot room and was presumably exposed to low concentrations of cadmium for 15 years.

One might also speculate if cadmium in the environment may have played some part in the observed excess of prostatic cancer in this area. Winkelstein and Kantor have suggested environmental cadmium exposure as a possible cause of prostatic cancer in urban areas, ${ }^{14}$ and the zinc and cadmium producing plant in Odda has for many years contributed to high concentrations of cadmium in the environment (Environmental Protection Committee of Odda, 1974).

Agents associated with electrometallurgical processes using carboneaceous electrodes might also be considered in this connection. Among employees in a ferrosilicon plant in another part of this project, 20 cases of prostatic cancer were observed versus 12.8 expected ${ }^{5}$ and an excess of prostatic cancer has also been observed in the ferrochromium industry. ${ }^{4}$ Occupational factors other than cadmium might therefore be important in the development of prostatic cancer.

The observed deficit of stomach cancer $(\mathrm{O} / \mathrm{E}=$ $5 / 10 \cdot 28)$ also deserves attention, as the incidence of stomach cancer in the rural parts of the county in which the plant is located was $25 \%$ higher than the national figures in the period $1972-6 .^{11}$ We have no $\frac{3}{8}$ definite explanation for this observation, but positive $\stackrel{\circ}{\stackrel{\circ}{\circ}}$ health selection of people without gastric symptoms $\Rightarrow$ for shift work might possibly have contributed to this $\stackrel{D}{\rightarrow}$ result. The occurrence of type 1 errors might also be considered for several of the observed associations. ${ }^{15}$ This project has been financed by the Health Board of $\frac{\mathbb{d}}{\Omega}$ the Norwegian Ferroalloy Industry. Unni Danielsen and Patricia Flor helped prepare the manuscript.

\section{References}

1 Tola S. Epidemiology of lung cancer in foundries. $J$ Toxicol Environ Health 1980;6:1195-200.

2 Blot WJ, Brown LM, Pottern LM, Stone BJ, Fraumeni JF. Lung cancer among long-term steel workers. Am J Epidemiol 1983; 117:706-16.

${ }^{3}$ Andersen A, Dahlberg BE, Magnus K, Wannag A. Risk of cancer is in the Norwegian aluminium industry. Int $J$ Cancer 1982; $\mathcal{V}$ 29:295-8.

${ }^{4}$ Langård S, Andersen A, Gylseth B. Incidence of cancer among ferrochromium and ferrosilicon workers. $\mathrm{Br} J$ Ind $\mathrm{Med} 1980$; 37:114-20.

${ }^{5}$ Kjuus H, Andersen A, Langård S, Knudsen KE. Cancer incidence among workers in the Norwegian ferroalloy industry. $\mathrm{Br} J$ Ind Med 1986;43:227-36.

${ }^{6}$ Weiss W. Heterogeneity in historical cohort studies: a source of bias $\mathscr{\infty}$ in assessing lung cancer risk. J Occup Med 1983;25:290-4.

${ }^{7}$ McMichael AJ. Standardized mortality ratios and the healthy worker effect: scratching beneath the surface. J Occup Med 1976;18:165-8.

${ }^{8}$ Axelson O. Aspects on confounding in occupational health epidemiology. Scand J Work Environ Health 1978;4:85-9.

${ }^{9}$ Selikoff IJ, Hammond EC, Seidman H. Cancer risk of insulation workers in the United States. In: Bogovski P, Gilson JC, Tim- $\overrightarrow{\vec{O}}$ brell V, Wagner JC, eds. Biological effects of asbestos. Lyon: International Agency for Research on Cancer, 1973:209-16. 3 (IARC scientific publ No 8.)

${ }^{10}$ Miller AB. Asbestos fibre dust and gastro-intestinal malignancies. Review of literature with regard to a cause/effect relationship. $J$ Chronic Dis 1978;31:23-33.

11 Cancer Registry of Norway. Geographical variations in cancer incidence in Norway 1966-1975. Oslo: Landsforeningen mot Kreft, 1978.

${ }^{12}$ Ernster VL, Selvin S, Brown SM, Sacks ST, Winkelstein W, Austin DF. Occupation and prostatic cancer. A review and retro- $O$ spective analysis based on death certificates in two California counties. J Occup Med 1979;21:175-83.

${ }^{13}$ Piscator M. Role of cadmium in carcinogenesis with special reference to cancer of the prostate. Environ Health Perspect $D$ 1981;40:107-20.

14 Winkelstein W, Kantor S. Prostatic cancer: relationship to suspended particulate air pollution. Am J Public Health 1969; م 59:1134-8.

${ }^{15}$ Dinman BD, Sussman NB. Uncertainty, risk, and the role of epidemiology in public policy development. J Occup Med 1983; $\mathcal{\omega}$ 25:511-6. 